\title{
The Role of TNF-alpha and IL-10 Cytokines in Degenerative Lumbar Spinal Stenosis
}

\author{
Mustafa Efendioğlu1, Emine Emel Koçman²
}

${ }^{1}$ Department of Neurosurgery, University of Health Sciences Turkey, Hamidiye Faculty of Medicine, Haydarpaşa Numune Health Application and Research Center, Istanbul, Turkey

${ }^{2}$ Department of Basic Immunology, University of Health Sciences Turkey, Hamidiye Faculty of Medicine, Haydarpaşa Numune Health Application and Research Center, Istanbul, Turkey

\begin{abstract}
Introduction: In this study, we investigated Tumor Necrosis Factor-a (TNF-a)/Interleukin -10 (IL-10) (inflammatory/anti-inflammatory) cytokine balance in patients diagnosed with degenerative Lumbar Spinal Stenosis (LSS).

Methods: Blood samples obtained from patients and control subjects were centrifuged at the Haydarpaşa Numune Training and Research Hospital Immunology Laboratory and stored at $-20^{\circ} \mathrm{C}$. Human TNF-alpha and IL-10 cytokines were studied manually with an Enzyme-linked immunosorbent assay (ELISA) method using Boster brand 96-well ELISA kits.

Results:TNF-alpha values of the patient group were found to be statistically significantly higher than the control group ( $p=0.004$; $p<0.05)$ and IL-10 values of the patient group were statistically significantly higher than the control group $(p=0.017 ; p<0.05)$.

Discussion and Conclusion: Our findings suggest that TNF-alpha and IL-10 cytokine levels increased together in degenerative LSS cases. The inflammatory process of the disease is trying to be balanced with an anti-inflammatory response.

Keywords: Cytokine; IL 10; lumbar spinal stenosis; TNF alpha.
\end{abstract}

$\mathrm{O}$ ne of the most important causes of low back pain in the elderly is lumbar spinal stenosis (LSS). LSS occurs as a result of compression of the neural structures under the pressure due to the narrowing of the central and/or lateral (foramen) in the spinal canal. LSS can be degenerative or congenital. Degenerative LSS is frequently seen in people over 50 years of age, and its symptoms include degeneration in discs, hypertrophy in facet joints, and hypertrophy of ligamentum flavum ${ }^{[1,2]}$.

There is limited information about the role of cytokines in degenerative LSS. Cytokines are small proteins that are se- creted between cells and act as messengers. Among proinflammatory cytokines, IL-1, IL- 6 and TNF-alpha are responsible for early responses in inflammation and stimulate the production of acute- phase proteins. Anti-inflammatory cytokines, such as IL-4, IL-10, IL-16 and TGF-beta, play a role in the inhibition of the production of proinflammatory cytokines and control inflammation ${ }^{[3]}$. On the other hand, it has been reported that the role of TGF- $\beta 1$ cytokine released from endothelial cells in the early stages of ligamentum flavum (LF) hypertrophy, plays a role in the pathogenesis of $\mathrm{LSS}^{[4-7]}$.

Correspondence (İletişim): Mustafa Efendioğlu, M.D. Saglik Bilimleri Universitesi, Hamidiye Tip Fakultesi, Haydarpasa Numune Saglik Uygulama ve Arastirma Merkezi, Beyin ve Sinir Cerrahisi Anabilim Dali, Istanbul, Turkey

Phone (Telefon): +90 5057745997 E-mail (E-posta): drefendioglu@gmail.com

Submitted Date (Başvuru Tarihi): 09.06.2020 Accepted Date (Kabul Tarihi): 10.06.2020

Copyright 2020 Haydarpaşa Numune Medical Journal

OPEN ACCESS This is an open access article under the CC BY-NC license (http://creativecommons.org/licenses/by-nc/4.0/) 
Although there are several recent articles describing changes in cytokine levels in degenerative spinal diseases, the role of cytokines in disease pathogenesis is still not fully disclosed. TNF- $\alpha$ is a cytokine that can stimulate inflammatory responses, induce nerve swelling and neuropathic pain, and promote cellular apoptosis through its cytotoxic effect. IL-10 is an anti-inflammatory with opposite effects, leads to a decrease in the immune response. In this study, we aimed to determine the inflammatory profile of the disease by measuring the levels of an inflammatory marker Tumor Necrosis Factor- $a$ (TNF-a) in degenerative LSS, and an anti-inflammatory marker interleukin -10 (IL-10) marker.

\section{Materials and Methods}

For this study, approval of the Ethics Committee of Health Sciences University Haydarpaşa Numune Training and Research Hospital was obtained (the decision number HNEAH - KAEK 2020/KK/18). Patients who applied to the outpatient clinics of the Department of Neurosurgery in our hospital with the complaints of low back pain and limitation of the movement were evaluated and informed consent was obtained for this study.

This study was conducted between 03.02.2019 and 06.30.2020 with a total of 64 patients whose ages ranged between 27 and 83 years. The study population consisted of $29(45.3 \%)$ male and 35 (54.7\%) female participants. The mean age of the cases was $54.53 \pm 13.57$ years. This study was carried out with 36 (56.3\%) patients and 28 (43.8\%) control subjects (Table 1). The exclusion criteria of this

Table 1. Evaluation of groups as for age, and gender of the participants

\begin{tabular}{lcccc}
\hline & $\begin{array}{c}\text { Patient } \\
\text { group }\end{array}$ & $\begin{array}{c}\text { Control } \\
\text { group }\end{array}$ & Total & p \\
\hline $\begin{array}{l}\text { Age, n (\%) } \\
\text { Gender, n (\%) } \\
\text { Male }\end{array}$ & $59.36 \pm 11.15$ & $48.32 \pm 14.06$ & $54.53 \pm 13.57$ & ${ }^{1} 0.001^{*}$ \\
$\quad$ Female & $18(50)$ & $11(39.3)$ & $29(45.3)$ & ${ }^{2} 0.548$ \\
\hline
\end{tabular}

${ }^{1}$ Student t-test; ${ }^{2}$ Continuity (Yates) correction; ${ }^{*} \mathrm{p}<0.05$. study were determined as congenital LSS, rheumatological low back pain, disc hernia, traumatic low back pain. Blood samples were drawn into the gel (yellow capped) tubes for measurement of cytokine levels and sent to the immunology laboratory of the hospital. The tubes were centrifuged and stored at $-20^{\circ} \mathrm{C}$. Cytokine measurements were performed manually with 96-well ELISA Kits (Boster Biological Technology, CA) by Human TNF-alpha (Catalog number: EK0525 PicoKine ELISA Kit) and IL-10 (Catalog number: EK0416 PicoKine ELISA Kit) Enzyme-linked immunosorbent assay (ELISA) methods The method was analyzed in Bio-Tek Elx800 reader.

The mean age of the patient group was statistically significantly higher than the control group $(p=0.001 ; p<0.05)$. There is no statistically significant difference between the groups concerning gender distribution rates ( $p>0.05$ ) (Table 1).

\section{Results}

The findings in this study are shown in Table 2, Figures 1 and 2.TNF -alpha values of the patient group were found to be statistically significantly higher than the control group $(p=0.004 ; p<0.05)$. IL-10 values of the patient group were found to be statistically significantly higher than the control group $(p=0.017 ; p<0.05)$.

\section{Statistical Analysis}

When evaluating the findings obtained in this study, IBM SPSS Statistics 22 for statistical analysis (SPSS IBM, Turkey) programs were used. While evaluating the study data, the fitness of the parameters to normal distribution was evaluated with the Shapiro Wilks test. While evaluating the study data, in addition to descriptive statistical methods (mean, standard deviation, frequency), Student's t-test was used for comparison of parameters that showed normal distribution, and in comparison of quantitative data, and Mann-Whitney $\mathrm{U}$ test was used for comparison between parameters that did not show normal distribution. Continuity (Yates) Correction was used to compare qualitative data. Level of statistical significance was evaluated at the level of $p<0.05$.

Table 2. Evaluation of groups as for TNF-alpha and IL-10 parameters

\begin{tabular}{lccc}
\hline & $\begin{array}{c}\text { Patient group } \\
\text { Mean } \pm \text { SD (median) }\end{array}$ & $\begin{array}{c}\text { Control group } \\
\text { Mean } \pm \text { SD (median) }\end{array}$ & $\begin{array}{c}\text { Total } \\
\text { Mean } \pm \text { SD (median) }\end{array}$ \\
\hline TNF alpha & $51.78 \pm 82.82(25.8)$ & $14.8 \pm 22.93(3.6)$ & $35.6 \pm 66.16(16.8)$ \\
IL-10 & $21.44 \pm 65.24(5)$ & $5.26 \pm 9.43(1.9)$ & $14.36 \pm 49.68(3.7)$ \\
\hline
\end{tabular}

Mann-Whitney U Test; ${ }^{p} p<0.05$. 


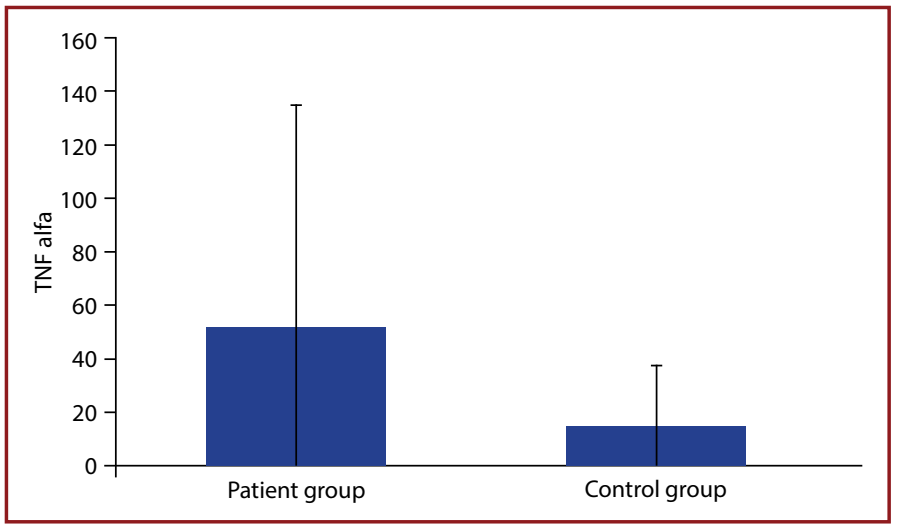

Figure 1. Comparison of the TNF-alpha levels in degenerative LSS and control groups.

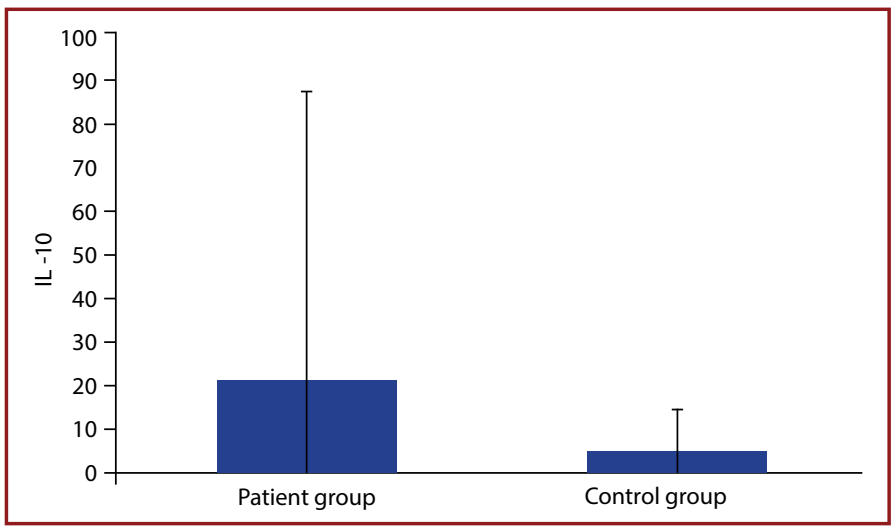

Figure 2. Comparison of the IL-10 levels in degenerative LSS and control groups.

\section{Discussion}

In studies on degenerative LSS, many proinflammatory cytokine levels have been found to be high, including TNF-a, IL-1, IL-6, IL-8, IL-17 and IFN-y ${ }^{[8-12]}$. Zhang et al. ${ }^{[13]}$ reported PDGF-BB expression, a high platelet-derived growth factor in pathological lumbar LSS. In another study, VEGF was thought to contribute to one of the pathogenetic mechanisms in $\mathrm{LSS}^{[14]}$. VEGF acts as a powerful regulator of many cellular functions, such as proliferation, differentiation, wound healing and angiogenesis.

In the previous studies, TNF-a and IL-6 were found to be highly responsible in the pathophysiology of low back pain. IL- 6 helps to mediate the acute phase response to injury by promoting monocyte differentiation. In contrast, higher IL-10 and IL-4 levels were found in painless neuropathy patients. This suggests that anti-inflammatory cytokines have analgesic effects, which may result in more appropriate treatment ${ }^{[15]}$.

In our study, TNF -alpha and IL-10 values of the patient group were found to be statistically significantly higher than the control group $(p=0.004 ; p<0.05$, and $p=0.017$; $p<0.05$, respectively). We found that concurrent increases in proinflammatory and anti-inflammatory cytokines increased indicating that an inflammatory process continued in patients with degenerative LSS and the opposite antiinflammatory response attempted to control this process was activated.

Ethics Committee Approval: The Ethics Committee of Haydarpaşa Numune Training and Research Hospital provided the ethics committee approval for this study (HNEAH-KAEK 2020/182060 - 10.02.2020).

Peer-review: Externally peer-reviewed.

Authorship Contributions: Concept: M.F., E.F.K.; Design: M.F.; Data Collection or Processing: M.F., E.F.K.; Analysis or Interpretation: M.F., E.F.K.; Literature Search: M.F., E.F.K.; Writing: M.F., E.F.K.

Conflict of Interest: None declared.

Financial Disclosure: The authors declared that this study received no financial support.

\section{References}

1. Ketenci A. Kronik bel ağrılı hastada ayıııı tanı. Totbid Dergisi 2017;16:118-25. [CrossRef]

2. Genevay S, Atlas SJ. Lumbar spinal stenosis. Best Pract Res Clin Rheumatol 2010;24:253-65. [CrossRef]

3. Ren L, Hu H, Sun X, Li F, Zhou JJ, Wang YM. The roles of inflammatory cytokines in the pathogenesis of ossification of ligamentum flavum. Am J Transl Res 2013;5:582-5.

4. Sairyo K, Biyani A, Goel V, Leaman G, Booth R, Thomas J, et al. Pathomechanism of ligamentum flavum hypertrophy: a multidisciplinary investigation based on clinical, biomechanical, histologic, and biologic assessments. Spine, 2005;30:2649-56.

5. Branton MH, Kopp JB. TGF-beta and fibrosis. Microbes Infect 1999;1:1349-65. [CrossRef]

6. Cunliffe IA, Rees RC, Rennie IG. The effect of TGF-beta 1 and TGF-beta 2 on the proliferation of human Tenon's capsule fibroblasts in tissue culture. Acta Ophthalmol Scand 1996;74:31-5. [CrossRef]

7. Chen J, Li Z, Chen H, Ji H, Deng C, Liu Z, et al. Transforming growth factor $\beta / S$ mad pathway participates in lumbar ligamentum flavum hypertrophy. Int J Clin Exp Pathol 2017; 10:5197-204.

8. Sutovsky J, Kocmalova M, Benco M, Kazimierova I, Pappova $\mathrm{L}$, Frano $\mathrm{A}$ et al. The role of cytokines in degenerative spine disorders. Eur J Pharm Sci 2017;6426-9. [CrossRef]

9. Le Maitre CL, Hoyland JA, Freemont AJ. Catabolic cytokine expression in degenerate and herniated human intervertebral discs: IL-1 beta and TNFalpha expression profile. Arthritis Res Ther 2007;9:R77. [CrossRef]

10. Weber KT, Alipui DO, Sison CP, Bloom O, Quraishi S, Overby $M C$, et al. Serum levels of the proinflammatory cytokine interleukin- 6 vary based on diagnoses in individuals with lumbar intervertebral disc diseases. Arthritis Res Ther 2016;18:3. [CrossRef] 
11. Johnson ZI, Schoepflin ZR, Choi H, Shapiro IM, Risbud MV. Disc in flames: Roles of TNF- $a$ and IL-1 $\beta$ in intervertebral disc degeneration. Eur Cell Mater 2015;30:104-16. [CrossRef]

12. Igarashi A, Kikuchi S, Konno S. Correlation between inflammatory cytokines released from the lumbar facet joint tissue and symptoms in degenerative lumbar spinal disorders. J Orthop Sci 2007;12:154-60. [CrossRef]

13. Zhang Y, Chen J, Zhong ZM, Yang D, Zhu Q. Is platelet-derived growth factor-BB expression proportional to fibrosis in the hypertrophied lumber ligamentum flavum? Spine (Phila Pa
1976) 2010;35:E1479-86. [CrossRef]

14. Jirathanathornnukul N, Limthongkul W, Singhatanadgige W, Parkpian V, Honsawek S. Increased expression of vascular endothelial growth factor is associated with hypertrophic ligamentum flavum in lumbar spinal canal stenosis. J Investig Med 2016;64:882-7. [CrossRef]

15. Khan AN, Jacobsen HE, Khan J, Filippi CG, Levine M, Lehman RA Jr, et al. Inflammatory biomarkers of low back pain and disc degeneration: a review. Ann N Y Acad Sci 2017;1410:68-84. 